\title{
Natural History Of Atopic Disease In Early Childhood: Is Cord Blood IgE A Prognostic Factor?
}

\section{A Preliminary Report}

\author{
Dr. S. Liptay \\ Prof. C. P. Bauer \\ Dr. A. Grübl \\ Dr. R. Franz \\ Prof. P. Emmrich
}

\section{Introduction}

$\mathrm{T}$ he natural history of atopic disease in early childhood is poorly defined. Previous studies in selected children suffering from atopic dermatitis, food allergy, or bronchial asthma report improvements ranging from $26 \%$ to $90 \% .8,15,17,23$ These findings are based on the follow-up of affected children, rather than a randomly selected population. Early accessible parameters such as family history $(\mathrm{FH})$ and sex, as well as clinical findings including time of onset, coincidence of different atopic diseases, and severity of the disease have been suggested to be of predictive value for the outcome of atopic dermatitis and bronchial asthma.

It is of particular interest to find factors predicting children at high

From the Kinderklinik und Poliklinik der Technischen Universität München, München, Federal Republic of Germany.

\footnotetext{
Address correspondence to: Dr. Susanne Liptay, Department of Internal Medicine, The University of Michigan

Medical Center, 1150 W. Medical Center Drive, MSRB II 3560, Ann Arbor, MI 48109-0688

(313) $763-5103$
}

risk of developing atopy soon after birth to start preventive programs in the immediate postnatal period. Therefore, predictive clinical parameters of established atopy, like time of onset, ${ }^{20}$ number of affected systems, ${ }^{4,20}$ and severity of the symptoms, ${ }^{23}$ might be helpful but are not of great benefit concerning preventive applications.

In this preliminary report, we studied prospectively the natural history of atopy during early childhood and investigated whether cord blood $\operatorname{IgE}$ (CB-IgE), FH, and sex are valuable parameters to predict the outcome of atopic disease in early childhood.

\section{Patients and Methods}

Two hundred children born in Munich at the Klinikum rechts der Isar der Technischen Universität München and at the Schwabinger Krankenhaus between September 1984 and February 1985 participated in the present prospective study. To ensure feasibility, only children born between 8 a.m. and 5 p.m. were included, if informed consent by the parents was obtained.

At birth, cord blood from the
200 newborns was collected. Serum for CB-IgE determination was separated and stored at $-20^{\circ} \mathrm{C}$ until assayed. Total IgE was measured by an enzyme immunoassay (Phadezym IgE Prist). All assays were carried out twice. The lower limit of sensitivity was $0.25 \mathrm{kU} / \mathrm{L}$. The coefficient of variation for intra- and interassay variability was below $5.5 \%$ for values between 0.25 and $13 \mathrm{kU} / \mathrm{L}$. A cut-off level of greater than $0.9 \mathrm{kU} / \mathrm{L}$ was chosen to distinguish between high and low CB-IgE concentrations. ${ }^{14}$

The parents were asked to answer questionnaires at the time of the child's birth, at 13 months ( \pm one month), and at three years ( \pm three months) after birth. At birth, the FH of possible atopic disease was obtained in 200 cases. After 13 months and three years, questionnaires were sent to all parents whose addresses could be traced. About $80 \%$ responded: 144 after 13 months $(n=181), 124$ after three years $(n=148), 112$ at both time points. Only the data of these 112 children were used for further analysis. The questions covered the family history of atopic disease and the child's own symptoms since the birth regarding skin, conjunctiva, respiratory and gastrointestinal 
tracts. Doubtful answers were checked by telephone interviews with the parents as well as the private pediatricians and, in addition, by clinical examination. Without knowledge of CB-IgE, current IgE serum levels, or the results of previous examinations we divided the children into the groups described below. The chi-square test was used in the statistical analyses. $P$ values of $<0.05$ were considered significant.

\section{Obvious Atopic Disease}

Atopic dermatitis: three or more basic features, plus three or more minor features, of the guidelines for the diagnosis of atopic disease by Hanifin and Rajka ${ }^{11}$ (not used was the feature "personal or family history of atopy").

Bronchial asthma: three or more episodes of bronchial obstruction, diagnosed at least once by a pediatrician. ${ }^{12}$

Allergic rhinitis: rhinitis and/or conjunctivitis two or more times after exposure to a particular allergen and unrelated to infection. ${ }^{12}$

Urticaria: acute, generalized urticaria two or more times after exposure to a particular allergen. ${ }^{12}$

Food allergy with acute gastrointestinal symptoms: any kind of gastrointestinal symptom (vomiting, diarrhea, abdominal pain, or colic) within two hours after food ingestion, verified by elimination and challenge study of the particular allergen. ${ }^{13}$

To decrease the inevitable misclassification of children based only on symptoms reported by questionnaires, we exclusively accepted children as obvious atopic if their symptoms were independently confirmed by two pediatricians who carried out the clinical examination in this study.

\section{Probable Atopic Disease}

Atopic dermatitis: pruritus and dry, squamous dermatitis. ${ }^{12}$
Bronchial asthma: two episodes of bronchial obstruction at least once diagnosed by a pediatrician and/or four or more episodes of bronchitis, pneumonia, or persistent coughing. ${ }^{12}$

Allergic rhinitis: nasal obstruction, episodes of sneezing more than five to 10 times in a row, rhinorrhea during at least four weeks unrelated to infection. ${ }^{21}$

Food allergy with acute gastrointestinal symptoms: four or more episodes of vomiting, diarrhea, abdominal pain, or colic within two hours after ingestion of a particular food. ${ }^{13}$

\section{Positive Family History of Atopy}

Previous or present symptoms of bronchial asthma, allergic rhinitis, atopic dermatitis, or allergic urticaria in first-degree relatives. To verify the accuracy of the answer, we registered a positive $\mathrm{FH}$ only if it was mentioned in at least two out of three questionnaires.

\section{Results}

Out of the 200 newborns participating in this study, $110(55 \%)$ were male, 90 newborns ( $45 \%$ ) were female. In 59 cases $(29.5 \%)$ a family history of atopy was reported. An increased level of CB-IgE $(>0.9 \mathrm{kU} / \mathrm{L})$ was determined in 21 infants $(10.5 \%)$.

During the first year of age, 144 children were available for followup analysis. Nineteen percent developed an obvious atopy, and $34 \%$ manifested a probable atopic disease(data not shown). After three years, 112 children remained in the study. Out of these, $16 \%$ suffered from an obvious atopic condition and $8 \%$ from a probable atopic disorder, while $76 \%$ had no atopic symptoms at three years of age (Table 1). Dropouts and children remaining in the study did not significantly differ regarding 
Table 2

\section{OBVIOUS, PROBABLE, OR NO ATOPIC DISEASE AT 3 YEARS OF AGE IN RELATION TO CORD BLOOD IgE (CB-IgE), FAMILY HISTORY, AND SEX}

$\begin{array}{lcc} & \begin{array}{c}\text { DIAGNOSIS } \\ \text { abvious } \\ \text { atopy }\end{array} & \begin{array}{c}\text { Probable } \\ \text { atopy }\end{array} \\ \text { Elevate } & 8(53 \%) & 4(27 \%) \\ \text { Norme } & 26(27 \%) & 26(27 \%) \\ \text { Positiv: } & 14(45 \%) & 11(36 \%) \\ \text { No FH } & 20(25 \%) & 19(23 \%) \\ \text { Male } & 18(31 \%) & 13(23 \%) \\ \text { Female } & 16(29 \%) & 17(31 \%)\end{array}$

sex, FH, or CB-IgE (respectively, $\mathrm{p}$ $>0.1$ ).

Children with increased CB-IgE or a FH of atopy developed obvious atopic disorders significantly more often during the first three years of age (respectively, $\mathrm{p}<0.025, \mathrm{p}<0.01$ ). Atopy was equally as frequent in both sexes $(\mathrm{p}>0.1)$ (Table 2$)$.

The patterns of the different atopic disorders determined after the first and third year are listed in Table 3. Ninety-six percent of all one-year-old children with an obvious atopic disease suffered from atopic dermatitis alone or in association with other atopic manifestations. In the third year, atopic dermatitis was still predominant, but decreased to $61 \%$ of all obvious cases, while bronchial asthma increased in incidence from $17 \%$ to $33 \%$. Urticaria was only observed in three-year-old children.

Of all children with an obvious or probable atopy in the first year of age $(n=58), 64 \%(n=37)$ recovered at the end of the study. On the other hand, only $11 \%(n=10)$ of healthy or probable-atopic oneyear-old children $(n=88)$ developed an obvious atopy during the next two years (Table 4). It is remarkable that $70 \%(\mathrm{n}=7)$ of these children $(n=10)$ already had a classification of probable atopic disorder at one year of age. Out of all children who showed obvious atopic symptoms at any time during this three-year study period $(n=34)$, only three children $(9 \%)$ developed the initial signs of atopy after one year of age.

Regarding the outcome of atopic diseases, we tested CB-IgE, $\mathrm{FH}$, and sex as prognostic parameters. From all obvious or probable atopic one-year-old infants who had a normal CB-IgE (CB-IgE $<0.9$ $\mathrm{kU} / \mathrm{L})$ at birth $(\mathrm{n}=47), 19 \%(\mathrm{n}=9)$ had an obvious and $6 \%(\mathrm{n}=3)$ a probable atopic disorder at three years of age. Seventy-five percent $(n=35)$ had recovered and showed no further symptoms of atopy. In contrast, only two children ( $18 \%)$ with obvious or probable atopy at one year of age and elevated CB$\mathrm{IgE}$ at birth became healthy during the follow-up period, while nine children $(82 \%)$ continuously suffered from an obvious (55\%) or probable $(27 \%)$ atopic disease (Table 5). Although we could only study a small number of atopic one-year-old patients with elevated CB-IgE, the association between $\mathrm{CB}-\mathrm{IgE}$ and outcome of atopy was significant $(\mathrm{p}<0.05)$.

In this study, the prognosis of atopy in early childhood was not influenced by the presence or absence of a positive $\mathrm{FH}(\mathrm{p}>0.1)$ (Table 5).

The outcome of atopy was significantly influenced by the sex of the children. Fifty-two percent of the boys with an obvious or probable atopic disease at one year of age showed continuously obvious or probable atopic symptoms, whereas $81 \%$ of the girls recovered $(\mathrm{p}<0.001)$ (Table 5).

\section{Discussion}

In this preliminary report we followed 200 newborns from birth up to three years of age; 112 children could be followed over the whole period.

The observed frequency of atopy in first-degree relatives and the frequency of increased CB-IgE levels are in agreement with previous reports. ${ }^{6,14}$ Our data strongly support the predictive value of these two parameters for subsequent development of atopy. ${ }^{6,14,16}$

Atopic disorders are common in early childhood. In the present study, the cumulated incidence of obvious atopy for the first three years of age was $30 \%$. Previous studies reported an incidence ranging from $24 \%$ to $34 \%$ in the first two years of life. ${ }^{7,18} \mathrm{~A}$ rather wide range of numbers is found in 
Table 3

\section{PATTERN OF ATOPIC MANIFESTATION AT 1 AND 3 YEARS OF AGE}

\section{DIAGNOSIS}

Alopic dermatinis

Bronchial asthro

Rhinitis

Immediate tood allergy

Urticaria

Double manifestation

Triple manifestation

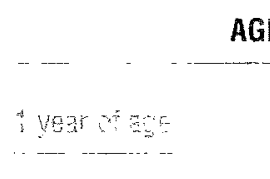

AGE developed initial signs of atopy after one year of age. This is in agreement with other studies which report a mean onset of atopy during the first year of age.$^{7 / 17}$ An explanation for this finding might be that the transient IgA deficiency occurring during the first months of infancy allows increased intestinal permeability and the access of ingested allergens to the immune system. ${ }^{19}$

There is an extreme variation in the literature concerning the outcome of atopic dermatitis, bronchial asthma, and food allergy. Reports of improvement ranged between 26\% and 90\%.15,17,23 Most studies reported recovery in about $50 \%$ of the cases..$^{5,8-10,19}$ In our study, two thirds of all obvious or probable atopic one-year-old infants recovered by three years of age. Explanations for this variation might be due to different study designs, as mentioned above.

Since the onset of atopic disease is most frequent during the first year of age, parameters to predict subsequent development of atopic disease and, more importantly, parameters to predict the outcome of the disease should be available as soon as possible after birth. Cord fication of symptoms merely based on questionnaires.

The pattern of atopic manifestation observed in this preliminary report is typical for the investigated age group. ${ }^{22}$ Atopic dermatitis was the predominant feature of atopy during the first and third year of age. At the third year, the number of children suffering from bronchial asthma and urticaria increased, whereas the prevalence of atopic dermatitis was diminished.

The natural history of atopic dermatitis, ${ }^{5,17,23}$ bronchial asthma, ${ }^{4,9,10}$ and food allergy ${ }^{2,8}$ has been studied only in preselected populations. There are no studies on unselected children and few on the natural history of the overall picture of atopic disease. ${ }^{22}$ Our data suggest that the risk of developing atopic diseases in early childhood is highest during the first year of age. Out of all children who developed an obvious atopic allergy at any time in the three-year study period, over two thirds showed obvious, and one fifth had probable, symptoms during the first year of age. In contrast, less than $10 \%$ of all observed children

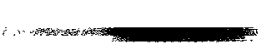


blood IgE can be determined immediately after birth. The measurement of $\operatorname{IgE}$ is sensitive, specific, reproducible, and of low cost. In addition to the well-established usefulness of $\mathrm{CB}-\mathrm{IgE}$ for the prediction of subsequent development of atopic disorders, ${ }^{6,14,16}$ our data support the value of CB-IgE as a prognostic parameter for the outcome of atopic disease. Children with normal $\mathrm{CB}-\mathrm{IgE}$ recovered significantly more frequently than children with elevated CB-IgE levels during the three-year observation. However, it is difficult to get definite evidence regarding the duration of atopic diseases in childhood with the present follow-up period, since there is the possibility that healthy children at three years of age could later drop back into the atopic disease group. Nevertheless, in our present study $\mathrm{CB}$ $\operatorname{IgE}$ predicts the outcome of atopy during the first three years of age. To clarify these results, a multicenter study with a longer follow-up period is in progress.

It has been suggested that the prognosis of atopic dermatitis and bronchial asthma is worse among children with a positive $\mathbf{F H} .{ }^{4}$ In the present study, we did not find an association between $\mathrm{FH}$ and the outcome of atopy. Our findings are in agreement with Businco et $\mathbf{a l}^{5}$ who concluded from their data that a positive $\mathrm{FH}$ was not a prognostic factor for atopic disease in childhood.

In this study the prognosis was affected by the sex of the child. Girls had a significantly better prognosis compared with boys. Previous reports indicate a better prognosis for boys, ${ }^{19}$ as well as for girls, ${ }^{17}$ or could not find any differences between sexes. ${ }^{10}$

The severity of symptoms at the onset, ${ }^{4}$ as well as the association of several atopic manifestations, ${ }^{4,19}$ are claimed by some investigators to indicate the outcome of atopy. Other studies have examined several other parameters, such as skin reactivity to allergens, $, 5,9,15$ and total $^{5,15}$ and specific $\operatorname{IgE},,^{15}$ for their value to predict the prognosis of atopy, but no correlation was found.

In summary, the present prospective study in randomly selected children presents evidence that the natural history of atopic disease is usually favorable and that CB-IgE is a valuable parameter to predict the outcome of atopic disease in early childhood. Cord blood IgE could be useful to select children at high risk of developing prolonged atopy for entry into preventive programs in the immediate postnatal period. In addition, knowing CB-IgE levels might be helpful in determining the intensity of the therapy and need of con- trols by the treating physician. To confirm the results of this preliminary report, a multicenter study is in progress.

\section{REFERENCES}

1. Astarita C, Harris RI, de Fusco R, et al. An epidemiological study of atopy in children. Clin Allergy. 1988;18:341-350.

2. Bahna SL. Milk allergy in infancy. Ann Allergy. 1987;59:131-136.

3. Berg T, Johansson SGO. IgE concentrations in children with atopic diseases. Int Arch Allergy. 1969;36:219-232.

4. Blair H. Natural history of childhood asthma. Arch Dis Child. 1977;52:613-619.

5. Businco L, Ziruolo MG, Ferrara M, et al. Natural history of atopic dermatitis in childhood: an updated review and personal experience of a five-year follow-up. Allergy. 1989;44(Suppl 9):70-78.

6. Croner S, Kjellman NIM, Erikson B, Roth A. IgE screening in 1701 newborn infants and the development of atopic disease during infancy. Arch Dis Child. 
1982;57:364-368.

7. Dannaeus A, Johansson SGO, Foucard T. Clinical and immunological aspects of food allergy in childhood. Acta Paediatr Scand. 1978;67:497-504.

8. Ford RPK, Taylor B. Natural history of egg hypersensitivity. Arch Dis Child. 1982;57:649-652.

9. Gerritsen J, Koeter GH, de Monchy JGR, Knol K Allergy in subjects with asthma from childhood to adulthood. $J$ Allergy Clin Immunol. 1990;85:116-125.

10. Gerritsen J, Koeter GH, Postma DS, et al. Prognosis of asthma from childhood to adulthood. Am Rev Respir Dis. 1989;140:1325-1330.

11. Hanifin JM, Rajka G. Diagnostic features of atopic dermatitis. Acta Dermatovener. 1980; Suppl 92:41-47.

12. Hattevig G, Kjellman NIM, Johansson SGO, Björksten B. Clinical symptoms and IgE responses to common food proteins in atopic and healthy chil- dren. Clin Allergy. 1984;14:551-559.

13. Kajosaari M, Saarinen UM. Prophylaxis of atopic disease by six months total solid food elimination. Acta Paediatr Scand. 1983;72:411-414.

14. Kjellman NIM, Croner S. Cordblood IgE determination for allergy prediction - a follow-up to seven years of age in 1651 children. Ann Allergy. 1984;53:167-171.

15. Linna O. A 5-year prognosis of childhood asthma. Acta Paediatr Scand. 1985;74:442-445.

16. Magnusson CGM. Cord serum IgE in relation to family history and as predictor of atopic disease in early infancy. Allergy. 1988;43:241-251.

17. Queille-Roussel C, Raynaud F, Saurat JH. A prospective computerized study of 500 cases of atopic dermatitis in childhood. Acta Derm Venerol. 1985;Suppl 114:87-92.

18. Savilahti E, Tainio VM, Salmenperä $\mathbf{L}$, et al. Prolonged exclusive breast feeding and heredity as determinants in infantile atopy. Arch Dis Child. 1987;62:269-273.

19. Soothill JF, Stokes CR, Turner MW, et al. Predisposing factors and the development of reaginic allergy in infancy. Clin Allergy. 1976;6:305-319.

20. Rystedt I. I ong term follow-up in atopic dermatitis. Acta Dermatovener. 1985; Suppl 114:117-120.

21. Van Asperen PP, Kemp AS, Mellis CM. A prospective study of the clinical manifestations of atopic disease in infancy. Acta Paediatr Scand. 1984;73:8085.

22. Van Asperen PP, Kemp AS. The natural history of $\operatorname{IgE}$ sensitisation and atopic disease in early childhood. Acta Paediair Scand. 1989;78:239-245.

23. Vickers CFH. The natural history of atopic eczema. Acta Dermatovener. 1980; Suppl 92:113-115. 